Ivy D. Patdu, MD, JD

National Privacy Commission Republic of the Philippines
Correspondence: Dr. Ivy D. Patdu

Deputy Commissioner

National Privacy Commission

Philippines

Phone: (632) 8042784

Email: ivypatdu@protonmail.com

The author declares that this represents original material, that the manuscript has been read and approved by the author, that the requirements for authorship have been met by the author, and that the author believes that the manuscript represents honest work.

Disclosures: The author signed a disclosure that there are no financial or other (including personal) relationships, intellectual passion, political or religious beliefs, and institutional affiliations that might lead to a conflict of interest.

\section{Recommendations for Social Media Use in Hospitals and Health Care Facilities}

Social Media is the new avenue for creating connections and sharing of information. Through social media, one can reach a global community. In recent years, we have seen how social media has changed the way we do things. Social Media has been extensively utilized for health education and promotion, proving itself to be an invaluable tool for public health, professional networking and patient care benefit.

The challenge has been to use the power afforded by social media responsibly, and to define the line between use and abuse. While there may be laws, implementation proves to be a challenge in the digital age. Therefore, self-regulation and institutional policy remain a critical part. It is therefore urged that hospitals and health care facilities adopt their own social media use policy appropriate for the institution.

Below are proposed rules that could guide institutions in developing their own policy for social media use:

Sec. 1. Declaration of Policy. The health facility recognizes that the exercise of the freedom of expression comes with a responsibility and a duty to respect the rights of others. The health facility likewise acknowledges the fundamental right to privacy of every individual. This policy shall provide rules for responsible social media use.

Sec. 2. Definition. For purposes of this policy, the following definitions shall be used:

a. Social Media refers to electronic communication, websites or applications through which users connect, interact or share information or other content with other individuals, collectively part of an online community. This includes Facebook, Twitter, Google+, Instagram, Linkedln, Pinterest, Blogs, Social Networking sites.

b. Health facility shall refer to the hospital or other health care facilities, including training and educational institutions.

c. Individual shall refer to physicians, employees, other health facility staff, residents, or students to which this policy would apply.

Sec. 3. Applicability. This policy shall apply to all physicians, health professionals, employees and other health facility staff, including students or residents in training, practicing their profession, working, or fulfilling academic and clinical requirements within the health facility, whether temporary or permanent. 
Sec. 4. General Principles. Social media use shall be guided by the following principles:

a. In using social media, an individual should always be mindful of his or her duties to the patient and community, his profession and his colleagues.

b. The individual should always be conscious of his or her online image and how it impacts his or her profession, or the institution where he or she is professionally employed, affiliated or otherwise connected.

c. Responsible social media use also requires the individual to ensure that in his or her social media activity, there is no law violated, including copyright, libel and cybercrime laws. At all times, the individual shall respect the right of privacy of others.

d. Use of social media requires a personal commitment to uphold the ethical standards required of those providing health services, upon which patient trust is built.

Sec. 5. Social Media for Health Education or Promotion

a. The individual using social media for health education or promotion must be well-informed of the matter subject of the social media post, comment or other activity. The individual shall refrain from any activity which spreads or tends to spread misinformation.

b. An article written by an individual and posted in social media must be evidence-based and disclose connections with pharmaceutical or health product companies or other sources of possible conflict of interest.

c. Social media shall not be used to dispense specific medical diagnosis, advice, treatment or projection but shall consist of general opinions only. Use of social media should include statements that a person should not rely on the advice given online, and that medical concerns are best addressed in the appropriate setting.

d. The individual shall be careful in posting or publishing his or her opinion and shall ensure that such opinion will not propagate misinformation or constitute a misrepresentation. The individual shall not make any misrepresentations in his or her social media activity relating to content, his or her employment or credentials, and any other information that may be misconstrued or taken out of context.

\section{Sec. 6. Professionalism in Social Media Use}

a. Individuals are discouraged from using a single account for both professional and private use. Be mindful that an electronic mail address used professionally may readily be linked to a social media site used privately.

b. The individual shall conduct himself or herself in social media or online the same way that he would in the public, mindful of acting in a manner befitting his profession, or that would inspire trust in the service he or she provides, especially if the individual has not separated his or her professional and personal accounts in social media.

c. The individual shall likewise refrain from using the name, logo or other symbol of an institution without prior authority in his or her social media activity. An individual shall not identify himself or herself as a representative of an institution in social media without being authorized to do so.

d. Individuals shall not accept former or current patients as friends or contacts in their personal accounts, unless there is justification to do so, such as a pre-existing relationship or when unavoidable for patient care. In case of online interaction with patients, this should be limited to matters related to the patient's treatment and management, and which could be properly disclosed.

e. Informal and personal information concerning a patient, colleague or the health facility shall not be posted, shared or otherwise used in social media.

f. Social media shall not be used to establish inappropriate relationships with patients or colleagues, and shall not be used to obtain information that would negatively impact on the provision of services and professional management of the patient.

g. An individual shall refrain from posting, sharing or otherwise using photos or videos taken within the health facility, which would give the impression of unprofessionalism, show parts of the health facility where there is an expectation of privacy, or those which includes colleagues, employees, other health facility staff, or patients without their express consent. The consent requirement shall apply even if the other individuals included are not readily identifiable.

\section{Sec. 7. Responsible Social Media Activity}

a. In using social media, the individual shall respect the dignity, personality, privacy and peace of mind of another.

b. The individual shall not post, share or otherwise use social media with the intent of damaging the reputation of any other individual or institution, especially if the subject is identified or identifiable.

c. Derogatory comments about patients, colleagues, employers and institutions or companies should be avoided. An individual may "like" a defamatory post but he or she must use caution 
when sharing, retweeting or contributing anything that might be construed as a new defamatory statement. A post, comment or other social media activity is considered defamatory if:

1) The activity imputes a discreditable act or condition to another;

2) The activity is viewed or seen by any other person;

3) The person or institution defamed is identified or readily identifiable;

4) There is malice or intent to damage the reputation of another.

d. He or she shall be careful of sharing posts or other contents that are unverified, particularly if it discredits another person or institution, or imputes the commission of a crime or violation of law even before trial and judgment, and violates the privacy of another. Fair and true reporting on matters of public concern shall be allowed provided that the content was obtained lawfully and with due respect for the right of privacy.

e. An individual shall not use copyrighted materials other than for fair use where there is proper citation of source and author. Use of copyrighted material for purpose of criticism, comment, news, reporting, teaching, scholarship, research, and similar purposes is compatible with fair use.

f. An individual is prohibited from:

1) Social media activities that defame, harass, stalk, or bully another person or institution.

2) The use or access of personal social media accounts of others without authority.

3) Posting, sharing or otherwise using any information intended to be private or obtained through access to electronic data messages or documents.

4) Posting, sharing or otherwise using recorded conversations between doctors, individuals or patients, when such recording, whether audio or video, was obtained without consent of all the parties to the conversation

g. Individuals should use conservative privacy settings in their social media account used professionally. The individual should also practice due diligence in keeping their social media accounts safe such as through regular password change and logging out after social media use.

Sec. 8. Health Information Privacy

a. The individual shall respect the right to privacy of others and shall not collect, use, access or disclose information, pictures and other personal or sensitive information without obtaining consent from the individual concerned. Physicians, health facility employees and other health staff shall have the duty of protecting patient confidentiality in their social media activity.

b. Personal health information, including photos or videos of patients, shall not be posted, shared or otherwise used in social media without consent of patient. Consent shall be obtained after explaining to the patient the purpose of the intended collection, use, access and disclosure. Consent for use of personal health information shall be written or evidenced by electronic means.

c. An individual shall not post, share or otherwise use any information which could be used to identify patients without their consent, including patient's location, room numbers, and photographs or videos of patients or their body parts, including code names referring to patients.

d. The individual shall not post, share or otherwise use any other information acquired in attending to a patient in a professional capacity, and which would blacken the reputation of the patient. The duty of maintaining patient confidentiality remains even after patient's death.

e. An individual shall not post, share or otherwise use any information relating to the identity, status and personal details of persons with HIV, those who have undergone drug rehabilitation, and victims of domestic violence, rape and child abuse.

\section{Sec. 9. Compliance and Reporting.}

a. An individual shall strive to develop, support and maintain a privacy culture in the health facility. He or she shall abide by the social media use policy of the institution.

b. An individual who becomes aware of unprofessional behavior, misinformation or privacy violations in social media shall report the matter to the hospital's privacy officer or the proper office or authority within the facility.

c. Health facilities shall in so far as practicable monitor the social media activity of all physicians, employees and other health facility staff, including students or residents in training, practicing their profession, working, or fulfilling academic and clinical requirements within the health facility, whether temporary or permanent.

Sec. 10. Penalty. A violation of this policy may constitute a violation of the code of ethics of physicians and other professions, and other applicable laws.

a. Health Professionals, employees and other Health Facility Staff. Any person found violating this policy will be considered in 
COMMENTARY

violation of health facility rules and regulations, and shall be subjected to health facility administrative proceedings, which after notice and hearing, and depending on the severity of the violation, could result to termination of service or withdrawal of privileges. A lighter penalty may likewise be imposed. In determining the severity of the violation, the following factors may be considered: previous violation, if any, the nature of the violation, and the extent of injury or damage.

The penalty imposed by the health facility shall be without prejudice to the filing of a complaint before the Civil Service
Commission, the Professional Regulations Commission, the Office of the Prosecutor or Ombudsman, or proper courts.

b. Students. In case of students, they shall be reported to the college wherein they are enrolled and shall be subjected to disciplinary proceedings, which could result to expulsion, depending on the severity of the violation, and in accordance with the applicable University and respective College rules. A lighter penalty may likewise be imposed. The disciplinary proceedings shall be without prejudice to other applicable legal remedies.

\section{REFERENCES}

1. 1987 Constitution of the Republic of the Philippines, Article III, Section 3(1) (1987)

2. An Act to Ordain and Institute the Civil Code of the Philippines, Republic Act No. 386, Article 26 (1950).

3. An Act Providing For The Recognition And Use Of Electronic Commercial And Non-Commercial Transactions And Documents, Penalties For Unlawful Use Thereof And For Other Purposes, (Electronic Commerce Act of 2000), Republic Act No. 8792, §§ 5, 7, 31-33 (2000).

4. An Act Protecting Individual Personal Information in Information and Communications Systems in the Government and the Private Sector, Creating for this purpose a National Privacy Commission, and for Other Purposes (Data Privacy Act of 2012), Republic Act No. 10173, (2012).

5. An Act to Prohibit and Penalize Wire Tapping and Other Related Violations of the Privacy of Communication, and for Other Purposes, (Anti Wire-Tapping Law), Republic Act No. 4200, §§ 1-2 (1965).

6. An Act Prescribing the Intellectual Property Code and Establishing the Intellectual Property Office, Providing for its Powers and Functions, and for Other Purposes, (Intellectual Property Code of the Philippines), Republic Act No. 8293, (1998).

7. An Act Promulgating Policies and Prescribing Measures for The Prevention and Control of HIV/Aids in The Philippines, Instituting A Nationwide HIV/Aids Information and Educational Program, Establishing A Comprehensive HIV/Aids Monitoring System, Strengthening The Philippine National Aids Council, And for Other Purposes, (Philippine AIDS Prevention and Control Act of 1998), Republic Act No. 8504, (1998).

8. An Act Instituting the Comprehensive Dangerous Drugs Act of 2002, Repealing Republic Act No. 6425, Otherwise Known as The Dangerous Drugs Act of 1972, As Amended, Providing Funds Therefor, And for Other Purposes, (Comprehensive Dangerous Act of 2002), Republic Act No. 9165, (2002)

9. An Act Providing Assistance and Protection for Rape Victims, Establishing for The Purpose a Rape Crisis Center in Every Province and City, Authorizing The Appropriation of Funds Therefor and for Other Purposes, (Rape Victim Assistance and Protection Act of 1998), Republic Act No. 8505, (1998).

10.Revised Rules on Evidence, Rules of Court, Rule 130, Section 24(c).

11.Hippocratic Oath, available at https://www.philippinemedicalassociation.org/downloads/ pma-codes/HIPPOCRATIC-OATH.pdf (last accessed May, 26, 2016).

12.Code ofEthics ofthePhilippineMedicalAssociationathttps://www.philippinemedicalassociation org/downloads/pma-codes/FINAL-PMA-CODEOFETHICS2008.pdf (last accessed May, 26, 2016).

13.Special Committee on Ethics and Professionalism. (2012, April). Model Guidelines for the Appropriate Use of Social Media and Social Networking in Medical Practice., at https://www. fsmb.org/Media/Default/PDF/FSMB/Advocacy/pub-social-media-guidelines.pdf (last accessed May 25, 2016).

14. Bristish Medical Association. Using social media: Practical and ethical guidance for doctors and medical students at http://bma.org.uk/-/media/Files/PDFs/Practical advice at work/Ethics/ socialmediaguidance.pdf (last accessed May 25, 2016).

15.Federation of State Medical Boards. Social Media Guidelines. At from www.fsmb.org/pdf/pub social-media-guidelines.pdf (last accessed May 25, 2016).

16.Patdu-Calaquian, I. D. (2015, December 1). "To Click or not to Click: Social Media and the MD" (Legal \& Ethical Issues for Doctors Using Social Media). Lecture presented at 59th Philippine Society of Otolaryngology-Head and Neck Surgery Annual Convention in Manila Marriott Hotel.

17.Patdu-Calaquian, I. D. (2014, May 6). "Facebook for Doctors: Use, Abuse, Misuse... Confused?". Lecture presented at 44th Annual PCP Convention in SMX Convention Center. 